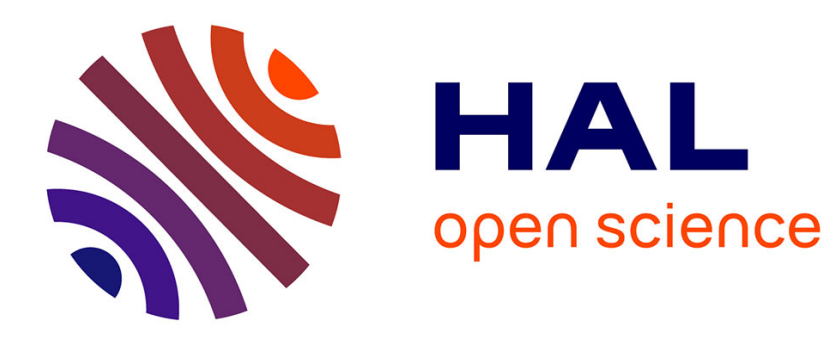

\title{
TRENDS AND CYCLES IN EURO AREA REAL GDP
}

\author{
Leigh Drake, T C Mills
}

\section{To cite this version:}

Leigh Drake, T C Mills. TRENDS AND CYCLES IN EURO AREA REAL GDP. Applied Economics, 2010, 42 (11), pp.1397-1401. 10.1080/00036840701721372 . hal-00591713

\section{HAL Id: hal-00591713 https://hal.science/hal-00591713}

Submitted on 10 May 2011

HAL is a multi-disciplinary open access archive for the deposit and dissemination of scientific research documents, whether they are published or not. The documents may come from teaching and research institutions in France or abroad, or from public or private research centers.
L'archive ouverte pluridisciplinaire HAL, est destinée au dépôt et à la diffusion de documents scientifiques de niveau recherche, publiés ou non, émanant des établissements d'enseignement et de recherche français ou étrangers, des laboratoires publics ou privés. 


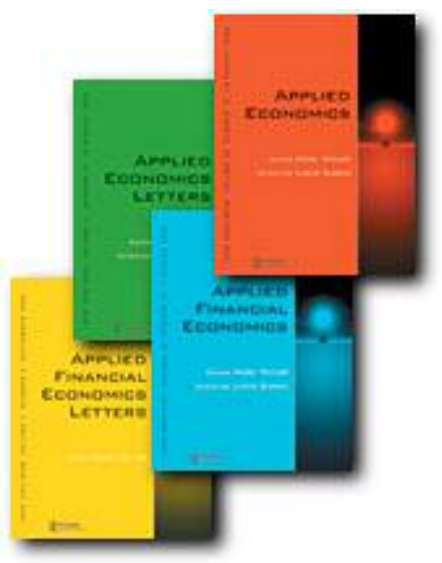

TRENDS AND CYCLES IN EURO AREA REAL GDP

\begin{tabular}{|c|c|}
\hline Journal: & Applied Economics \\
\hline Manuscript ID: & APE-06-0679.R1 \\
\hline Journal Selection: & Applied Economics \\
\hline $\begin{array}{r}\text { Date Submitted by the } \\
\text { Author: }\end{array}$ & 28-Sep-2007 \\
\hline Complete List of Authors: & $\begin{array}{l}\text { Drake, Leigh; Nottingham University, Business School } \\
\text { Mills, T; Loughborough University, Department of Economics }\end{array}$ \\
\hline JEL Code: & $\begin{array}{l}\text { E32 - Business Fluctuations|Cycles \&lt; E3 - Prices, Business } \\
\text { Fluctuations, and Cycles \&lt; E - Macroeconomics and Monetary } \\
\text { Economics, F15 - Economic Integration \&lt; F1 - Trade \&lt; F - } \\
\text { International Economics }\end{array}$ \\
\hline Keywords: & Euro Area, Business Cycle, Band Pass Filter \\
\hline
\end{tabular}

\section{今) ScholaroNE \\ Manuscript Central}




\title{
Trends And CyCles in Euro Area Real GDP
}

\author{
Leigh Drake* \\ Nottingham University Business School \\ and \\ Terence C. Mills \\ Department of Economics, Loughborough University \\ Revised \\ September 2007
}

\begin{abstract}
This paper examines the time series properties of real GDP in the Euro area (EU 11), both prior to and after the adoption of the Euro in January 1999. We employ the relatively recent "optimal approximation" band pass filter developed by Christiano and Fitzgerald (2003) in order to identify a Euro-zone business cycle. We also utilise two alternative assumptions regarding the behaviour of the trend component of Euro area real GDP. The empirical results suggest that the single currency experiment appears to have reduced trend growth in the Euro zone, both ex-ante during the Maastricht nominal convergence phase, and also ex-post, during the period 2001Q1 to 2005Q4. With respect to cyclical behaviour, we identify a very robust measure of the Euro zone business cycle in the post 1994 period which does not appear to be sensitive to the particular assumption made regarding the trend rate of growth of real GDP. This type of result should facilitate a more accurate assessment of the extent to which individual countries and groups of countries are converged with respect to the Euro area business cycle.
\end{abstract}

Key words: Euro Area; Business Cycle; Band Pass Filter

JEL Categories: E32; F15

\footnotetext{
* Corresponding auther: Jubilee Campus, Wollaton Road, Nottingham, NG8 1BB, UK Tel: +44 (0) 115846 7415, Fax: +44 (0) 1158466667

E-mail: leigh.drake@nottingham.ac.uk
} 
The countries within the European Union (EU) have become increasingly integrated in recent decades. Following the inception of the Common Market under the Treaty of Rome in 1957 we have witnessed: the introduction of the European Monetary System (EMS) in 1979; the onset of the Single Market in 1992 (covering goods, services, labour and capital); the signing of the Maastricht Treaty in 1992, and the introduction of the single currency, the Euro, in January 1999. Although the EU has certainly become more integrated in recent years, there is a continuing debate over the extent of convergence across the EU countries, and most especially across the countries participating in the single currency. Furthermore, this debate has intensified recently with the accession of a further ten countries into the EU and the expectation that they will ultimately join the single currency, the Euro zone.

Following the seminal contribution of the theory of Optimal Currency Areas (OCAs) by Mundell (1961), business cycle convergence and the absence of asymmetric shocks has been considered as an important pre-requisite for a successful monetary union. Subsequent analysis, such as Frankel and Rose (1998), however, has stressed that OCAs may be endogenous, in the sense that a group of countries adopting a single currency may be more likely to satisfy the OCA criteria ex-post rather than ex-ante. This is also the view of the European Commission (1990), who have argued that real macroeconomic convergence is more likely ex-post given the stimulus to intra-industry trade provided by the adoption of the single currency. A contrary view has been proposed by Krugman (1991), however, who argues that the combination of trade integration and economies of scale is likely to result in industrial concentration and clustering, as in the U.S., which may well exacerbate asymmetric shocks and hence undermine real macroeconomic convergence.

A further contentious issue is the potential impact of the adoption of the Euro on growth in the Euro zone economy. Once again, there is an ex-ante and ex-post aspect to this issue. From an ex-ante perspective, there is the possibility that, for many of the countries wishing to participate in the single currency, the nominal convergence criteria set out in the Maastricht Treaty imposed a severe deflationary policy bias which may have acted to reduce economic growth. There is also the possibility that the continuing imposition of the Stability and Growth Pact, and the consequent restriction on Government fiscal deficits relative to GDP, may have 
reduced economic growth, at least in the short term, after the introduction of the Euro. It is also possible that the alleged benefits of monetary unions (such as the elimination of transactions costs, the boost to intra-industry trade, the potential reduction in real interest rates and the stimulation of investment expenditure, etc.) may have acted to enhance economic growth ex-post.

The main purpose of this paper, therefore, is to examine the time series properties of real GDP in the Euro area as a whole, both prior to and after the adoption of the Euro in January 1999. The sample period is 1980Q1 to 2005Q4 and covers the EU-11 countries which were the initial adopters of the Euro. Of particular interest is the decomposition of the real GDP series into trend and cyclical components. This is a key issue in respect of any business cycle convergence analysis as the aggregate Euro zone cycle provides an ideal benchmark for comparison against the cycles of individual countries. To date, most of the convergence analysis has consisted of comparing the cycles of individual countries (for example, Dickerson et al, 1998, and Wynne and Koo, 2000) or comparing these cycles with benchmark countries such as Germany (see, for example, Artis and Zhang, 1997, 1999). Given that the European Central Bank (ECB) sets monetary policy in the context of the Euro zone economy as a whole, however, it can be argued that it is the extent to which individual countries' business cycles are converged with that of the Euro zone as a whole which is of paramount importance from an OCA perspective. Hence, although the analysis of Euro zone convergence is beyond the scope of this current paper, a thorough analysis of the time series properties, and in particular the trend and cycle decomposition of the Euro zone real GDP series, is of great policy relevance.

In addition, by offering a fresh perspective on the decomposition of Euro area real GDP into trend and business cycle components, we aim to provide a perspective on whether the adoption of the Euro has had any impact on trend real GDP growth in the Euro area, both ex-ante and ex-post.

\section{Data}

The univariate analysis conducted in this paper relates to real GDP (seasonally adjusted) for the aggregate Euro zone economies. As mentioned previously, the sample period is $1980 \mathrm{Q} 1$ to $2005 \mathrm{Q} 4$ and relates to the EU-11 economies. We utilise the official data produced by the ECB from 1990Q1. Prior to this date, however, no 
official data is available and we utilise the Euro area database constructed by Gollinelli, and we gratefully acknowledge the use of this data. This data has been constructed (and verified) to be consistent with the official ECB data (see Gollinelli and Pastorello, 2000, for further details). Plots of the logarithms of this series, denoted $q_{t}$, and the annual growth rates (computed as $100\left(q_{t}-q_{t-4}\right)$ are shown in Figure 1 and show several features that are of interest and importance in any decomposition of the series into trend and cyclical components. While the series exhibits a secular increase with an average rate of growth per quarter of $0.5 \%$ (approximately $2 \%$ per annum), this growth rate is by no means constant. In the early years of the 1980s growth was nonexistent but picked up quite rapidly during the later years of the decade. There was a pronounced downturn during 1992, whereupon growth picked up once again, remaining fairly stable until 2001, whereupon there was a growth slowdown.

\section{Trend-Cycle Decompositions of Real GDP}

In this section we consider trend-cycle decompositions of real GDP of the form $q_{t}=\tau_{t}+c_{t}+\varepsilon_{t}$, where $\tau_{t}, c_{t}$ and $\varepsilon_{t}$ are the trend, cycle and irregular (short-run) components of $q_{t}$, assumed to be independent of each other. As is now common in the business cycle literature, we require that $c_{t}$ captures those components of $q_{t}$ that have frequencies in the range of 1.5 to 8 years ( 6 to 32 quarters). This component can be estimated by a band pass filter: the filter that we actually use is the 'optimal approximation' of Christiano and Fitzgerald (2003), which has been shown to be superior to the traditional Hodrick and Prescott (1997) filter and the Baxter and King (1999) band pass filter in several respects. In particular, the asymmetric version employed here is better at estimating the cycle in real time, i.e., at and near the end of the sample period, which is important when attention is focused on identifying recent and current cyclical movements, as would be the case here.

Of course, construction of any cyclical filter requires assumptions about the behaviour of the trend component. We construct our cyclical component under two very different assumptions about the trend behaviour of $q_{t}$. First, we consider that $q_{t}$ follows an ARIMA process, so that the underlying trend is stochastic. The model so identified is an $\operatorname{ARIMA}(1,1,0)$ with drift 


$$
\Delta q_{t}=\underset{ }{(0.0007)(0.094)} \quad \hat{\sigma}_{a}=0.00489
$$

Standard errors are shown in parentheses and $\hat{\sigma}_{a}$ is the estimated standard error of the white noise $a_{t}$. Thus trend growth averages $0.38 /(1-0.226)=0.49 \%$ per quarter (1.96\% per annum) and the filter proposed in Christiano and Fitzgerald (2003, section 2 ) is approximately optimal. Figure 2 shows the stochastic trend that is obtained from this filter (the cycle is discussed later). The trend is seen to evolve over time in line with the discussion above.

An alternative trend assumption is that it evolves as a deterministic function. Given our earlier discussion of the evolution of $q_{t}$, a simple linear (or indeed higher order polynomial) trend is unappealing. However, a segmented linear trend of the type originally analysed by Fuller (1976, chapter 9.2) produces a satisfactory fit:

$$
\begin{aligned}
& q_{t}=6.877+0.0073 \varphi_{1 t}-0.0123 \varphi_{2 t}+0.0110 \varphi_{3 t}-0.0025 \varphi_{4 t}+e_{t}
\end{aligned}
$$

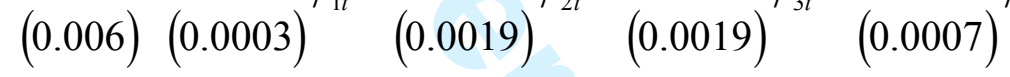

$$
\begin{aligned}
& e_{t}=0.834 e_{t-1}+a_{t} \quad \hat{\sigma}_{a}=0.00422 \\
& (0.057) \\
& \varphi_{i t}=\left\{\begin{array}{cl}
t-\tau_{i}, & t>\tau_{i} \\
0, & t \leq \tau_{i}
\end{array} \quad i=1, \ldots, 4\right.
\end{aligned}
$$

where

$$
\tau_{1} \equiv 1983 \mathrm{Q} 1 \quad \tau_{2} \equiv 1992 \mathrm{Q} 1 \quad \tau_{3} \equiv 1993 \mathrm{Q} 1 \quad \tau_{4} \equiv 2000 \mathrm{Q} 4
$$

Here five segments are fitted and their selection follows the evolution of the series discussed above. The fitted trend is shown in Figure 3. Trend growth is zero until 1983Q1 and then $0.73 \%$ per quarter (3\% per annum) until 1992Q1. The downturn during 1992 is then modelled as a trend change, with a decrease of $0.5 \%$ per quarter (2\% per annum). From 1993 to $2001 \mathrm{Q} 1$ trend growth was $0.59 \%$ per quarter $(2.3 \%$ per annum), after which growth declined to $0.34 \%$ per quarter ( $1.4 \%$ per annum). Hence, the evidence provided in Figure 3 reinforces the finding from the stochastic trend specification that the adoption of the Euro appears to have reduced the trend rate of growth of the Euro zone economies, both ex-ante and ex-post. Specifically, annual 
trend growth during the Maastricht convergence period was only around $2.3 \%$ per annum, in contrast to 3\% between 1983Q1 and 1992Q1. Furthermore, the trend growth rate declined further to only 1.4\% per annum in the post-2001Q1 period.

In the context of the segmented linear trend, the innovations to the trend are modelled by a stationary first order autoregressive process. Since the residuals, defined as $e_{t}=q_{t}-\tau_{t}=c_{t}+\varepsilon_{t}$, are by definition stationary, the cyclical component $c_{t}$ can be calculated by applying the stationary Christiano and Fitzgerald filter to $e_{t}$.

The cyclical components estimated by the two methods are shown in Figure 4. Since 1994 the two cycles are very similar to each other. The cycles are very different to each other between 1992 and 1994 because the segmented trend model treats the decline of 1992 and subsequent rebound as a pair of trend shifts whereas the random walk model allocates this movement to the cycle. Less severe differences are also seen before 1992, again because the models allocate shifts to trend and cycle differently.

The evidence presented in Figures 2 to 4 suggests that the deflationary impact of the Maastricht Treaty from early 1992 contributed to the very large cyclical downturn evident in the early 1990s, but also reduced the trend rate of growth during the 1990s relative to that which prevailed for most of the 1980s. With respect to the introduction of the Euro, the evidence suggests that the trend rate of growth from early 2001 has been reduced relative to the mid to late 1990s, and especially relative to the late $1980 \mathrm{~s}$. It is clearly inappropriate to attribute this recent slowdown in growth solely to the impact of the single currency. The initial growth slowdown is likely to be attributable in large part to the impact of the "high tech shock" and the subsequent general slowdown in the world economy after 2001. Nevertheless, it seems likely that many countries in the Euro-zone, faced with this general slowdown in world economic growth, were unable to allow their automatic stabilisers to work in the traditional fashion due to the imposition of the Stability and Growth Pact. Clearly, this will have compounded the loss of an independent monetary policy and exchange rate under the single currency and may well have transformed a cyclical downturn in the Euro zone economies into a further decline in trend growth.

The fact that the two alternative methods produce very similar cycles in the post-1994 period gives us some confidence that we have identified a robust and definitive Euro-zone business cycle for this period. Clearly, this should prove 
extremely useful in the context of subsequent business cycle convergence analysis, i.e., the extent to which individual countries or groups of countries have business cycles which are synchronised or converging with the Euro-zone business cycle.

With respect to business cycle chronology, both cycles suggest a business cycle peak in 1995 followed by a double dip recession during 1996/97 and 1998/99. The latter may well be attributable to the deflationary impact of the Maastricht convergence criteria ahead of the decision on Euro eligibility in 1997. It is the case, for example, that, due to the construction of the inflation convergence requirements, the average inflation rate in the potential Euro zone countries was continually driven downwards until 1998/99. The very stringent fiscal convergence requirements, however, necessitated very tight fiscal as well as monetary policies and it was not until 1996, for example, that the Euro zone economies in aggregate managed to reduce the ratio of Government debt to GDP. Finally, conformation of the fact that the impact of the convergence process was most pronounced in the post-1996 period is confirmed by the fact that short term interest rates across the Euro-zone began to converge with those of Germany's over this period. Hence, the pronounced deflationary impact of the Maastricht nominal convergence requirements may well have been sufficient to "snuff out" the economic recovery evident during 1996 / 97 and produce the double dip recession during 1998 / 99.

Interestingly, the launch of the single currency in January 1999 coincided with a strong cyclical upturn in the Euro-zone economies with a business cycle peak in early 2001. Aside from any positive benefits attributable to the single currency itself, this may also reflect the fact that the countries in the Euro zone were effectively freed from the deflationary constraints of the Maastricht convergence criteria after 1997 and hence the abortive economic recovery of 1996 / 97 belatedly materialised across the Euro zone. The subsequent downturn ended in mid-2003 and, during the latter part of the sample, the Euro area was still experiencing a steady cyclical recovery which previous evidence suggests will probably have been completed by mid-2006.

\section{$4 \quad$ Summary and Conclusions}

In this paper we employ the 'optimal approximation' band pass filter developed by Christiano and Fitzgerald (2003) to identify a Euro-zone business cycle in real GDP. We also utilise two alternative assumptions regarding the behaviour of the trend 
component of Euro area real GDP. In both cases, it is evident that the single currency experiment appears to have been associated with reduced trend growth in the Euro zone relative to the period 1983 to 1992, both ex-ante during the Maastricht nominal convergence phase, and also ex-post, during the period 2001Q1 to 2005Q1.

With respect to the cyclical behaviour of Euro zone real GDP, there are considerable differences between the cycles from the segmented and stochastic trend models during the earlier part of the sample period, most especially during 1992. From 1994, however, the two cycles are very closely synchronised. This suggests that we have identified a very robust measure of the Euro zone business cycle in the post 1994 period which does not appear to be sensitive to the particular assumption made regarding the trend rate of growth of real GDP. This should facilitate a more accurate assessment of the extent to which individual countries and groups of countries are converged with respect to the Euro area business cycle. As the ECB makes monetary policy decisions with respect to the Euro zone as a whole, such analysis is important in the context of any analysis of Europe as an OCA. 


\section{References}

Artis, M.J. and Zhang, W. (1997), "International Business Cycles and the ERM: Is There a European Business Cycle", International Journal of Finance and Economics, 38, 1471-1487.

Artis, M.J. and Zhang, W. (1999), "Further Evidence on the International Business Cycle and the ERM: Is There a European Business Cycle?", Oxford Economic Papers, 23, 120-132.

Baxter, M. and King, R.G. (1999), "Measuring Business Cycles: Approximate BandPass Filters for Economic Time Series", Review of Economics and Statistics $81,575-593$.

Christiano, L.J. and Fitzgerald, T.J. (2003), "The Band Pass Filter", International Economic Review 44. 435-465.

Dickerson, A.P., Gibson, H.D, and Tsakalatos, E. (1998), "Business Cycle Correspondence in the European Union”, Empirica, 25, 51-77.

EC Commission (1990), “One Market, One Money”, European Economy, 44.

Frankel, J. and Rose, A. (1998), "The Endogeneity of the Optimal Currency Area Criterion", Economic Journal, 108, 1009-1025.

Fuller, W.A. (1976), Introduction to Statistical Time Series. New York: Wiley.

Gollinelli, R. and Pastorello, S. (2000), "The Euro Area Countries Database: A Statistical Appendix", mimeo, Department of Economics, University of Bologna, Italy, June.

Hodrick, R.J. and Prescott, E.C. (1997), "Postwar U.S. Business Cycles: An Empirical Investigation", Journal of Money, Credit and Banking 29, 1-16.

Krugman, P. (1991), Geography and Trade, Cambridge, Mass.: MIT Press.

Mundell, R.A. (1961), "A Theory of Optimum Currency Areas," American Economic Review, 51, 657-665.

Wynne, M. and Koo, J. (2000), "Business Cycles under Monetary Union: A Comparison of the EU and US", Economica 67, 347-374. 

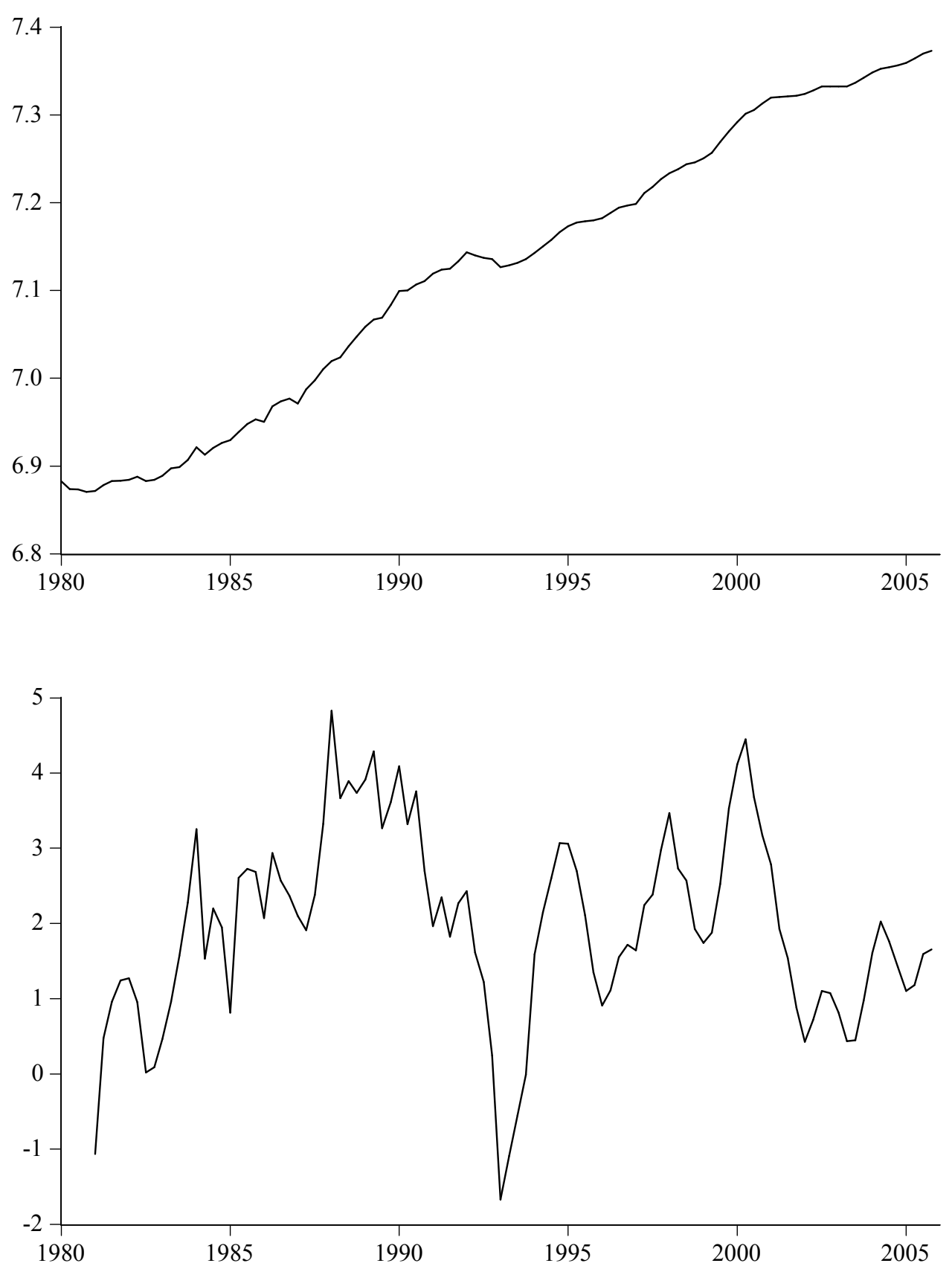

Figure $1 \quad$ Real Euro-GDP; $1980.1-2005.4$. Top panel: logarithms: $q_{t}$. Bottom panel: annual growth rates, $100\left(q_{t}-q_{t-4}\right)$. 


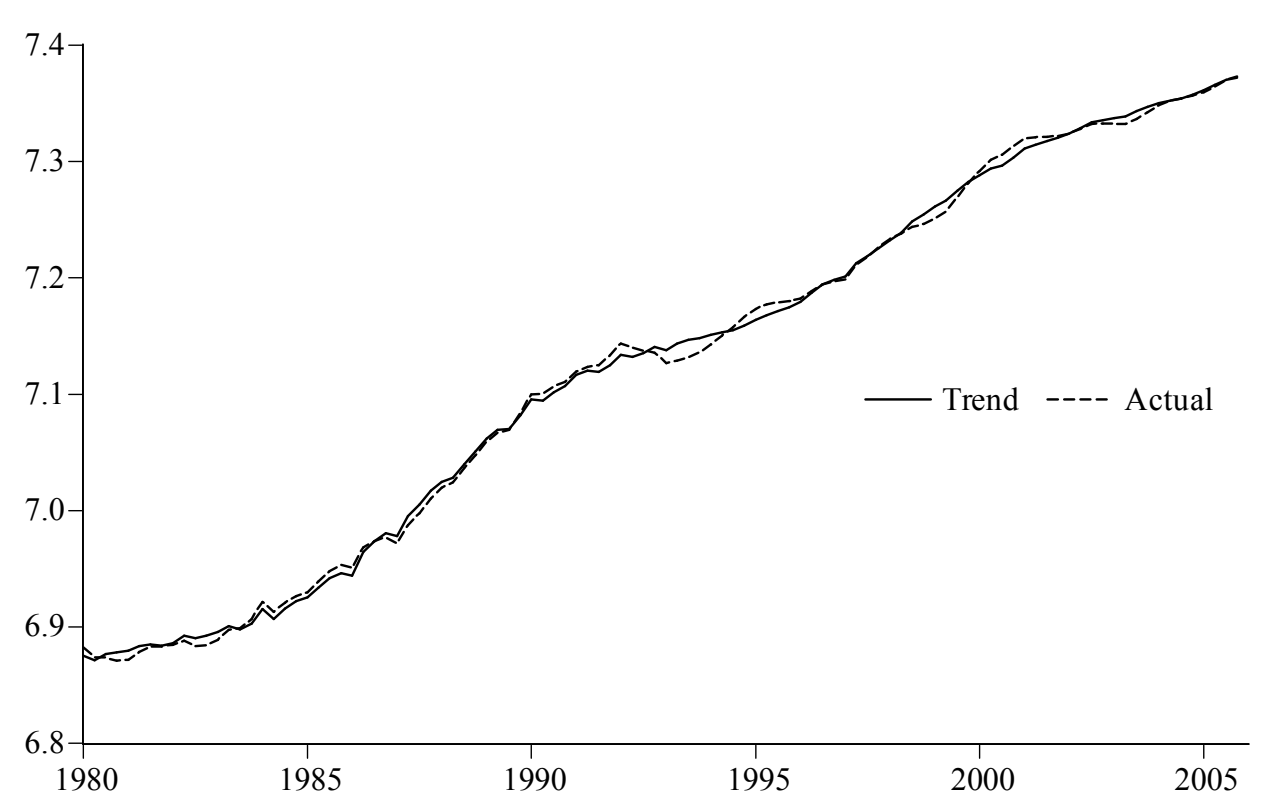

Figure 2 Band pass trend fitted to $q_{t}$.

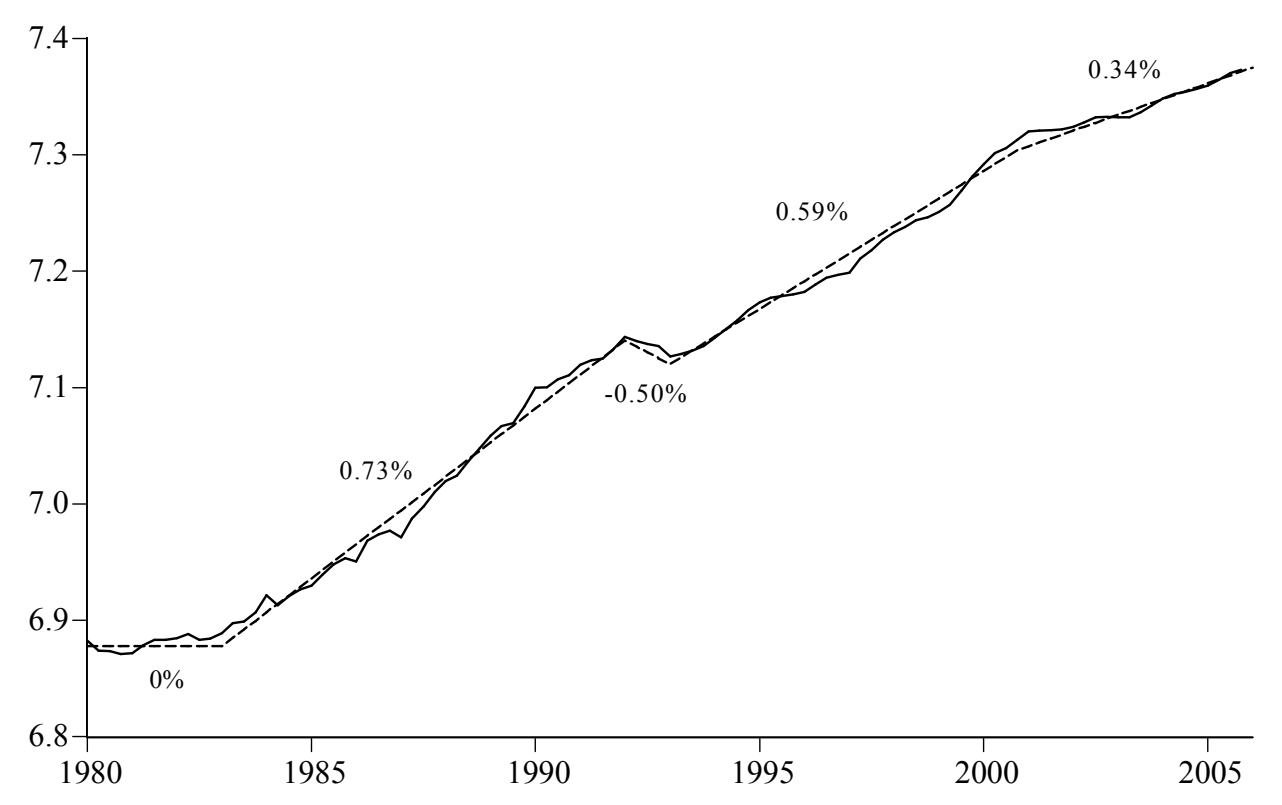

Figure 3 Segmented trend with growth rates. 


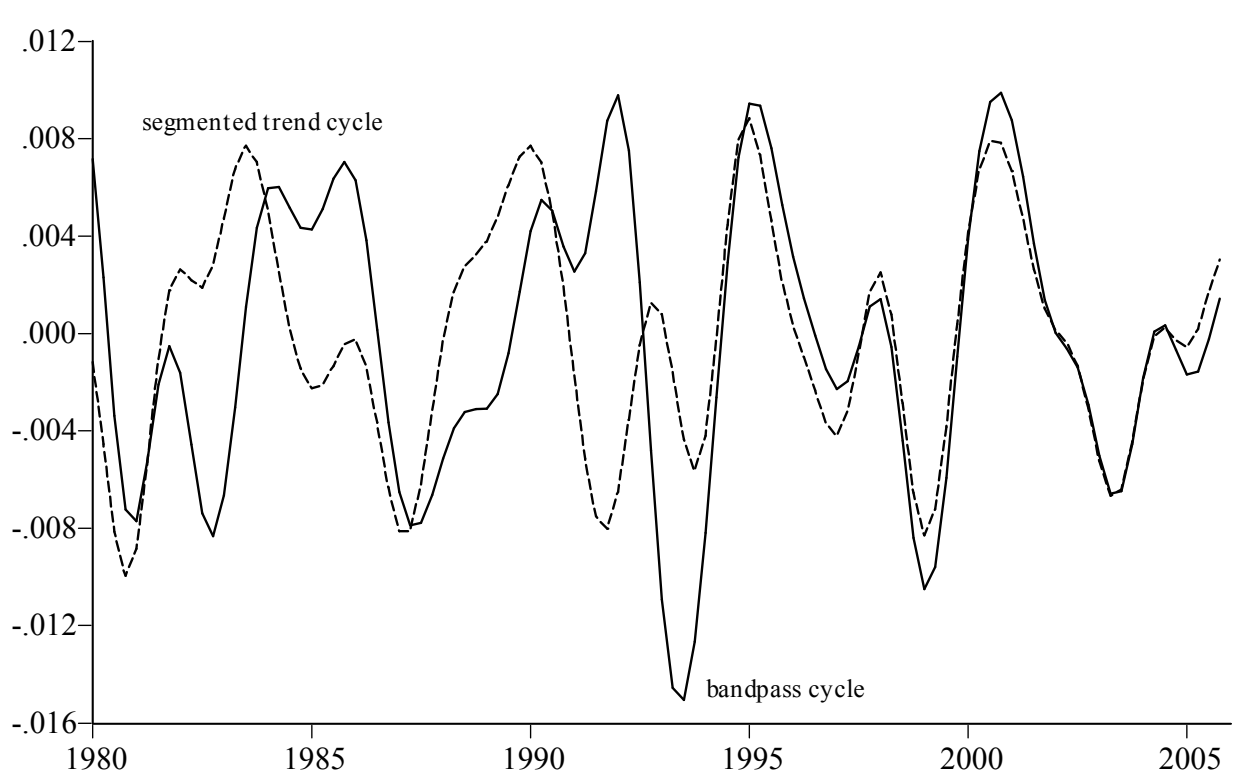

Figure 4 Cyclical components from the two models. 


\title{
Trends ANd CyCles in Euro Area ReAl GDP
}

\author{
Leigh Drake* \\ Professor of Financial Economics \\ Nottingham University Business School \\ and \\ Terence C. Mills \\ Professor of Applied Statistics and Econometrics \\ Department of Economics, Loughborough University \\ Loughborough, LE11 $3 T U$
}

\section{November 2006}

\begin{abstract}
This paper examines the time series properties of real GDP in the Euro area as a whole, both prior to and after the adoption of the Euro in January 1999 . We employ the relatively recent "optimal approximation" band pass filter developed by Christiano and Fitzerald (2003) in order to identify a Euro-zone business cycle. We also utilise two alternative assumptions regarding the behaviour of the trend component of Euro area real GDP. The empirical results suggest that the single currency experiment appears to have reduced trend growth in the Euro zone, both ex-ante during the Maastricht nominal convergence phase, and also ex-post, during the period 2001Q1 to 2006Q1. With respect to cyclical behaviour, we identify a very robust measure of the Euro zone business cycle in the post 1994 period which does not appear to be sensitive to the particular assumption made regarding the trend rate of growth of real GDP.
\end{abstract}

Key words: Euro Area; Business Cycle; Band Pass Filter

JEL Categories: E32; F15

\footnotetext{
* Corresponding auther: Jubilee Campus, Wollaton Road, Nottingham, NG8 1BB, UK Tel: +44 (0) 1158467415 , Fax: +44 (0) 1158466667

E-mail: leigh.drake@nottingham.ac.uk
} 
The main purpose of this paper is to examine the time series properties of real GDP in the Euro area as a whole, both prior to and after the adoption of the Euro in January 1999. Of particular interest is the decomposition of the real GDP series into trend and cyclical components. This is a key issue in respect of any business cycle convergence analysis as the aggregate Euro zone cycle provides an ideal benchmark for comparison against the cycles of individual countries. To date, most of the convergence analysis has consisted of comparing the cycles of individual countries (for example, Dickerson et al, 1998, and Wynne and Koo, 2000) or comparing these cycles with benchmark countries such as Germany (see, for example, Artis and Zhang, 1997, 1999). Given that the European Central Bank (ECB) sets monetary policy in the context of the Euro zone economy as a whole, however, it can be argued that it is the extent to which individual countries' business cycles are converged with that of the Euro zone as a whole which is of paramount importance from an Optimal Currency Area (OCA) perspective (see Mundell, 1961). Hence, although the analysis of Euro zone convergence is beyond the scope of this current paper, a thorough analysis of the time series properties, and in particular the trend and cycle decomposition of the Euro zone real GDP series, is of great policy relevance.

In addition, by offering a fresh perspective on the decomposition of Euro area real GDP into trend and business cycle components, we aim to provide a perspective on whether the adoption of the Euro has had any impact on trend real GDP growth in the Euro area, both ex-ante and ex-post.

\section{Data}

The univariate analysis conducted in this paper relates to real GDP (seasonally adjusted) for the aggregate Euro zone economies. The sample period is 1980Q1 to 2006Q1 and relates to the EU-11 economies until 2000Q4 and the EU-12 economies from 2001Q1, following the entry of Greece into the Euro zone. We utilise the official data produced by the ECB from 1990Q1. Prior to this date, we utilise the Euro area database constructed by Gollinelli, and we gratefully acknowledge the use of this data. This data has been constructed (and verified) to be consistent with the official ECB data (see Gollinelli and Pastorello, 2000, for further details). A plot of 
the logarithms of this series, denoted $q_{t}$, is shown in Figure 1 and shows several features that are of interest and importance in any decomposition of the series into trend and cyclical components. While the series exhibits a secular increase with an average rate of growth per quarter of $0.5 \%$ (approximately $2 \%$ per annum), this growth rate is by no means constant. In the early years of the 1980s growth was nonexistent but picked up quite rapidly during the later years of the decade. There was a pronounced downturn during 1992, whereupon growth picked up once again, remaining fairly stable until the Euro-zone entry of Greece in 2001Q1 produced both an immediate jump in real GDP followed by a growth slowdown.

\section{Trend-Cycle Decompositions of Real GDP}

In this section we consider trend-cycle decompositions of real GDP of the form $q_{t}=\tau_{t}+c_{t}+\varepsilon_{t}$, where $\tau_{t}, c_{t}$ and $\varepsilon_{t}$ are the trend, cycle and irregular (short-run) components of $q_{t}$, assumed to be independent of each other. As is now common in the business cycle literature, we require that $c_{t}$ captures those components of $q_{t}$ that have frequencies in the range of 1.5 to 8 years ( 6 to 32 quarters). This component can be estimated by a band pass filter: the filter that we actually use is the 'optimal approximation' of Christiano and Fitzgerald (2003), which has been shown to be superior to the traditional Hodrick and Prescott (1997) filter and the Baxter and King (1999) band pass filter in several respects. In particular, the asymmetric version employed here is better at estimating the cycle in real time, i.e., at and near the end of the sample period, which is important when attention is focused on identifying recent and current cyclical movements, as would be the case here.

Of course, construction of any cyclical filter requires assumptions about the behaviour of the trend component. We construct our cyclical component under two very different assumptions about the trend behaviour of $q_{t}$. First, we consider that $q_{t}$ follows an ARIMA process with an additive outlier at 2001Q1 to model the inclusion of Greece into the Euro-zone, so that the underlying trend is stochastic. The model so identified is a random walk with drift

$$
\begin{aligned}
& \Delta q_{t}=0.0048+0.0172 \varphi_{t}+a_{t} \quad \hat{\sigma}_{a}=0.00523 \\
& (0.0005)(0.0053)
\end{aligned}
$$


where the additive outlier is defined as $\varphi_{t}=\mathbf{1}(2001 Q 1), \mathbf{1}(\cdot)$ being the indicator function. (Standard errors are shown in parentheses and $\hat{\sigma}_{a}$ is the estimated standard error of the white noise $a_{t}$.) Thus trend growth averages $0.48 \%$ per quarter $(1.9 \%$ per annum), with the entry of Greece producing a one-off increase in the growth rate of $1.72 \%$. The adjusted series

$$
q_{t}^{*}= \begin{cases}q_{t} & t \leq 2000 \mathrm{Q} 4 \\ q_{t}-0.0172 & t \geq 2001 \mathrm{Q} 1\end{cases}
$$

then follows a pure random walk with drift, for which the filter proposed in Christiano and Fitzgerald (2003, section 2) is then optimal. Figure 2 shows the stochastic trend that is obtained from this filter (the cycle is discussed later). The trend is seen to evolve over time in line with the discussion above.

An alternative trend assumption is that it evolves as a deterministic function. Given our earlier discussion of the evolution of $q_{t}$, a simple linear (or indeed higher order polynomial) trend is unappealing. However, a segmented linear trend of the type originally analysed by Fuller (1976, chapter 9.2) produces a satisfactory fit:

$$
\begin{gathered}
q_{t}=\begin{array}{l}
6.987+0.0074 \varphi_{1 t}-0.0124 \\
(0.005)(0.0002)
\end{array} \varphi_{2 t}+0.0108 \varphi_{3 t}+0.0169 \varphi_{4 t}-0.0194 \varphi_{5 t}+e_{t} \\
e_{t}=0.810 e_{t-1}+a_{t} \\
(0.061) \\
\varphi_{i t}=\left\{\begin{array}{cl}
t-\tau_{i}, & t>\tau_{i} \\
0, & t \leq \tau_{i}
\end{array} \quad \hat{\sigma}_{a}=0.00425\right. \\
\end{gathered}
$$

where

$$
\begin{array}{lll}
\tau_{1} \equiv 1983 \mathrm{Q} 1 & \tau_{2} \equiv 1992 \mathrm{Q} 1 & \tau_{3} \equiv 1993 \mathrm{Q} 1 \\
\tau_{4} \equiv 2000 \mathrm{Q} 4 & \tau_{5} \equiv 2001 \mathrm{Q} 1 &
\end{array}
$$

Here six segments are fitted (the fifth is equivalent to the additive outlier modelling the Greek entry) and their selection follows the evolution of the series discussed 
above. The fitted trend is shown in Figure 3. Trend growth is zero until 1983Q1 and then $0.74 \%$ per quarter (3\% per annum) until 1992Q1. The downturn during 1992 is then modelled as a trend change, with a decrease of $0.5 \%$ per quarter ( $2 \%$ per annum). From 1993 to Greek entry in 2001Q1 trend growth was $0.58 \%$ per quarter $(2.3 \%$ per annum), after which growth declined to $0.43 \%$ per quarter (1.7\% per annum). Hence, the evidence provided in Figure 3 reinforces the finding from the stochastic trend specification that the adoption of the Euro appears to have reduced the trend rate of growth of the Euro zone economies, both ex-ante and ex-post. Specifically, annual trend growth during the Maastricht convergence period was only around $2.3 \%$ per annum, in contrast to 3\% between 1983Q1 and 1992Q1. Furthermore, the trend growth rate declined further to only $1.7 \%$ per annum in the post-2001Q1 period.

In the context of the segmented linear trend, the innovations to the trend are modelled by a stationary first order autoregressive process. Since the residuals, defined as $e_{t}=q_{t}-\tau_{t}=c_{t}+\varepsilon_{t}$, are by definition stationary, the cyclical component $c_{t}$ can be calculated by applying the stationary Christiano and Fitzgerald filter to $e_{t}$.

The cyclical components estimated by the two methods are shown in Figure 4. Since 1994 the two cycles are very similar to each other. The cycles are very different to each other between 1992 and 1994 because the segmented trend model treats the decline of 1992 and subsequent rebound as a pair of trend shifts whereas the random walk model allocates this movement to the cycle. Less severe differences are also seen before 1992, again because the models allocate shifts to trend and cycle differently.

The evidence presented in Figures 2 to 4 suggests that the deflationary impact of the Maastricht Treaty from early 1992 contributed to the very large cyclical downturn evident in the early 1990s, but also reduced the trend rate of growth during the 1990s relative to that which prevailed for most of the 1980s. With respect to the introduction of the Euro, the evidence suggests that the trend rate of growth from early 2001 (after the entry of Greece into the Euro) has been reduced relative to the mid to late 1990s, and especially relative to the late 1980s. This may reflect the fact that many countries in the Euro-zone, faced with the general slowdown in the world economy after 2001, were unable to allow their automatic stabilisers to work in the traditional fashion due to the imposition of the Stability and Growth Pact. Clearly, 
this will have compounded the loss of an independent monetary policy and exchange rate under the single currency.

The fact that the two alternative methods produce very similar cycles in the post-1994 period gives us some confidence that we have identified a robust and definitive Euro-zone business cycle for this period. Clearly, this should prove extremely useful in the context of subsequent business cycle convergence analysis, i.e., the extent to which individual countries or groups of countries have business cycles which are synchronised or converging with the Euro-zone business cycle.

With respect to business cycle chronology, both cycles suggest a business cycle peak in 1995 followed by a double dip recession during 1996/97 and 1998/99. Interestingly, the launch of the single currency in January 1999 coincided with a strong cyclical upturn in the Euro-zone economies with a business cycle peak in early 2001. The subsequent downturn ended in mid-2003 and the Euro area is still experiencing a steady cyclical recovery which previous evidence suggests will probably be complete by mid- 2006 .

\section{Summary and Conclusions}

The evidence produced in this paper suggests that the single currency experiment appears to have reduced trend growth in the Euro zone relative to the period 1983 to 1992, both ex-ante during the Maastricht nominal convergence phase, and also expost, during the period 2001Q1 to 2006Q1.

With respect to the cyclical behaviour of Euro zone real GDP, there are considerable differences between the cycles from the segmented and stochastic trend models during the earlier part of the sample period, most especially during 1992. From 1994, however, the two cycles are very closely synchronised. This suggests that we have identified a very robust measure of the Euro zone business cycle in the post 1994 period which does not appear to be sensitive to the particular assumption made regarding the trend rate of growth of real GDP. This should facilitate a more accurate assessment of the extent to which individual countries and groups of countries are converged with respect to the Euro area business cycle. As the ECB makes monetary policy decisions with respect to the Euro zone as a whole, such analysis is important in the context of any analysis of Europe as an OCA. 


\section{References}

Artis, M.J. and Zhang, W. (1997), "International Business Cycles and the ERM: Is There a European Business Cycle", International Journal of Finance and Economics, 38, 1471-1487.

Artis, M.J. and Zhang, W. (1999), "Further Evidence on the International Business Cycle and the ERM: Is There a European Business Cycle?", Oxford Economic Papers, 23, 120-132.

Baxter, M. and King, R.G. (1999), "Measuring Business Cycles: Approximate BandPass Filters for Economic Time Series", Review of Economics and Statistics $81,575-593$.

Christiano, L.J. and Fitzgerald, T.J. (2003), “The Band Pass Filter”, International Economic Review 44. 435-465.

Dickerson, A.P., Gibson, H.D, and Tsakalatos, E. (1998), "Business Cycle Correspondence in the European Union”, Empirica, 25, 51-77.

Fuller, W.A. (1976), Introduction to Statistical Time Series. New York: Wiley.

Gollinelli, R. and Pastorello, S. (2000), "The Euro Area Countries Database: A Statistical Appendix", mimeo, Department of Economics, University of Bologna, Italy, June.

Hodrick, R.J. and Prescott, E.C. (1997), "Postwar U.S. Business Cycles: An Empirical Investigation", Journal of Money, Credit and Banking 29, 1-16.

Mundell, R.A. (1961), "A Theory of Optimum Currency Areas," American Economic Review, 51, 657-665.

Wynne, M. and Koo, J. (2000), "Business Cycles under Monetary Union: A Comparison of the EU and US", Economica 67, 347-374. 


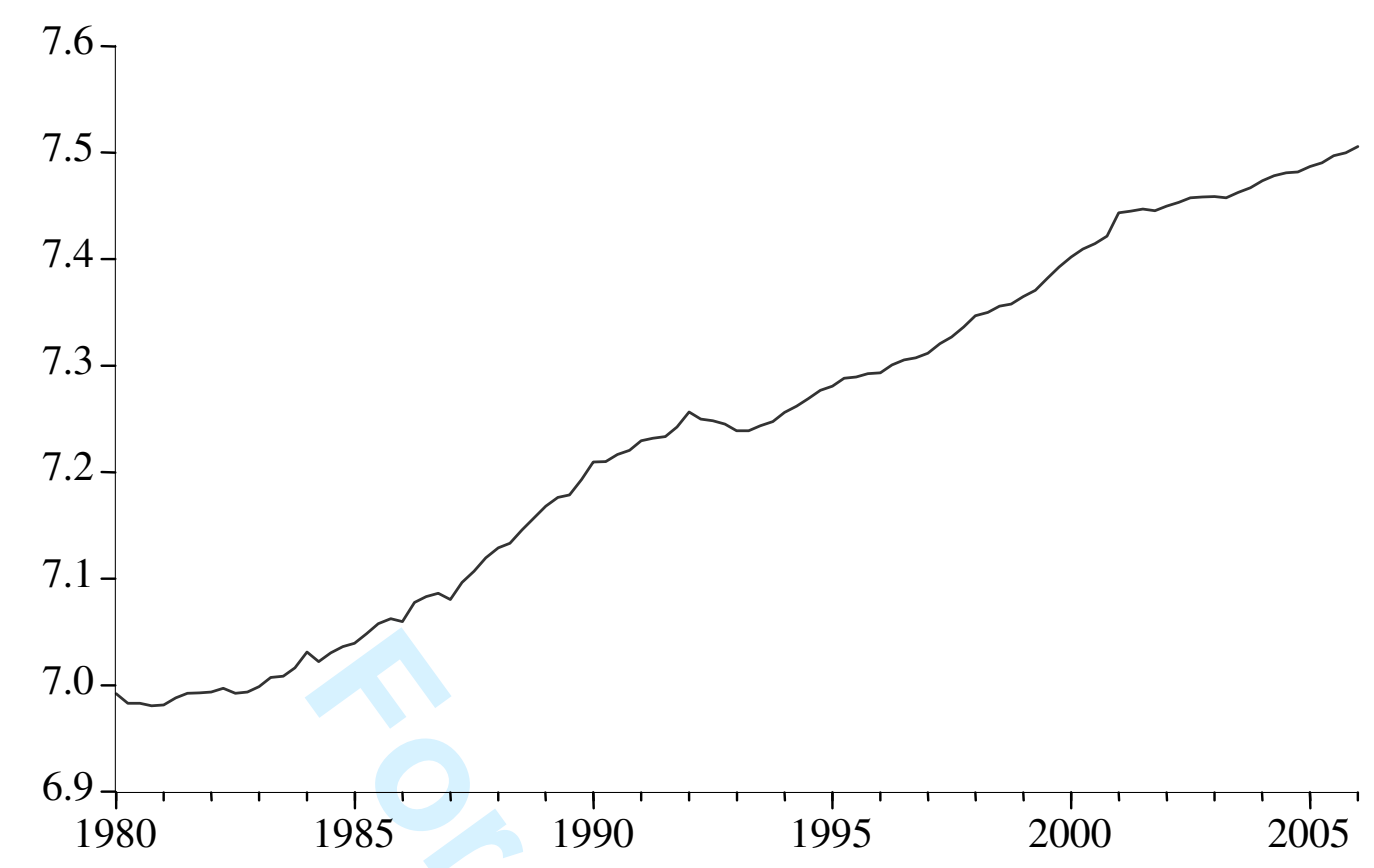

Figure $1 \quad$ Real Euro-GDP; 1980.1 - 2006.1 (logarithms: $q_{t}$ )

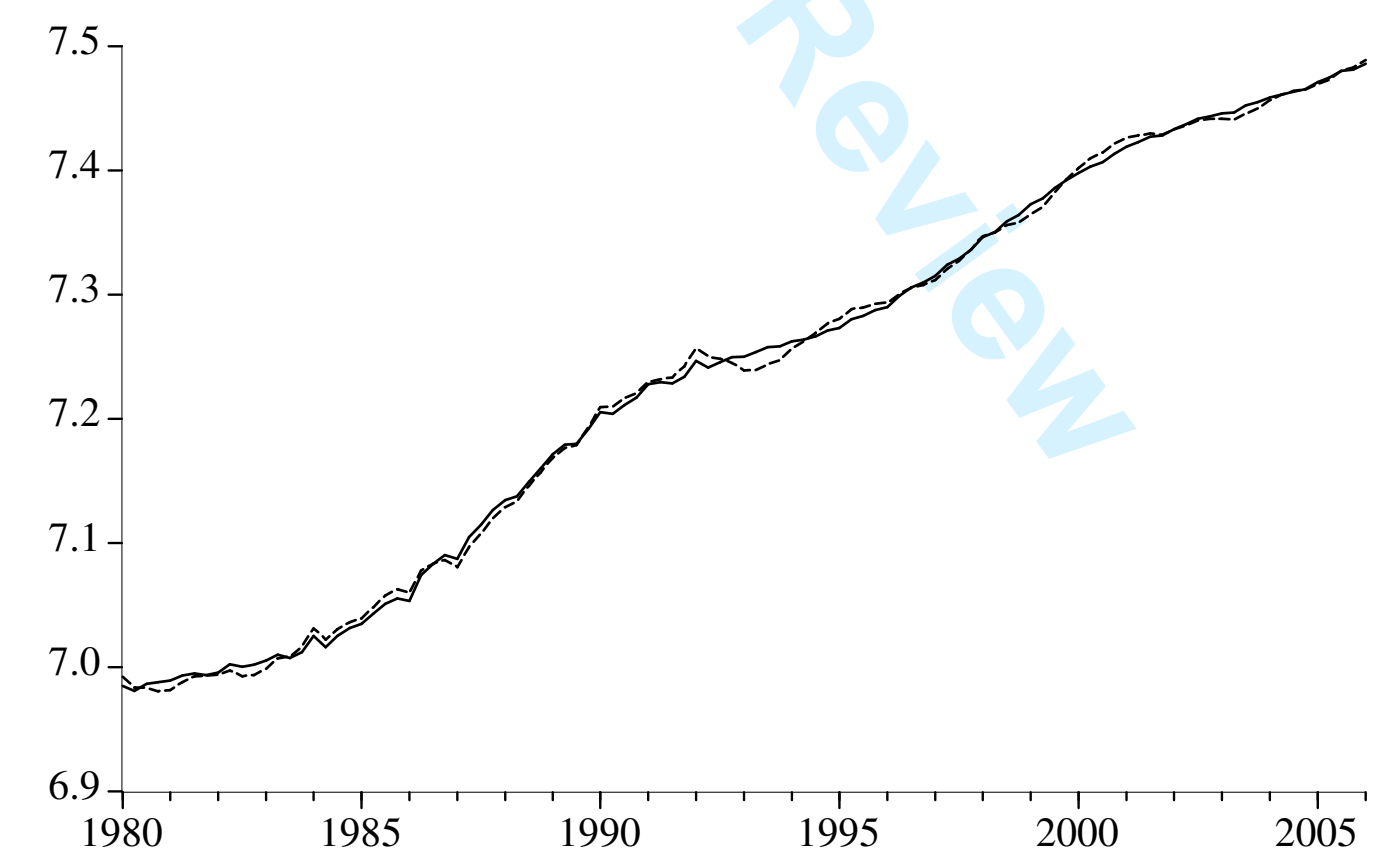

Figure 2 Band pass trend fitted to $q_{t}^{*}$. 


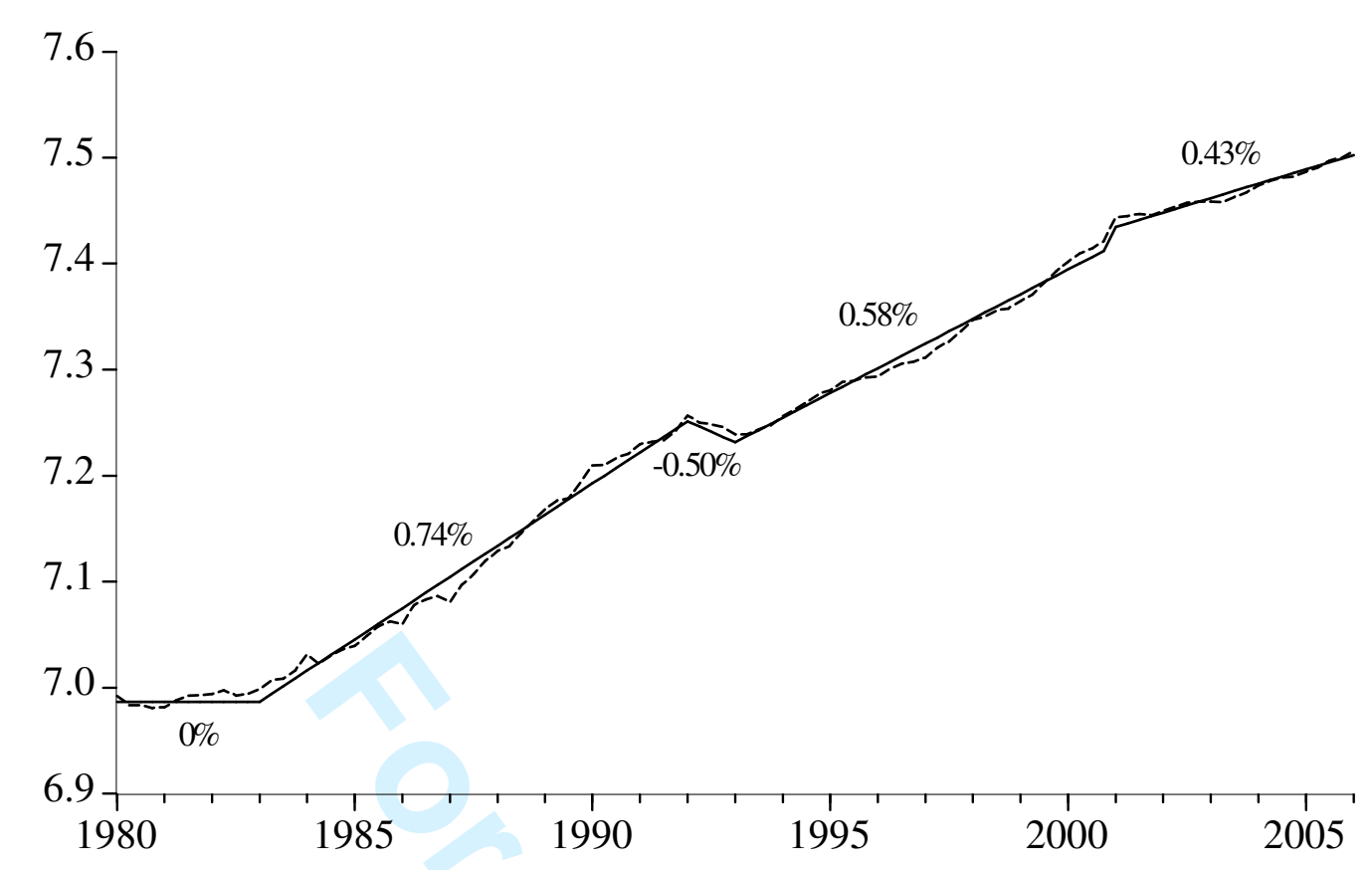

Figure 3 Segmented trend with growth rates.

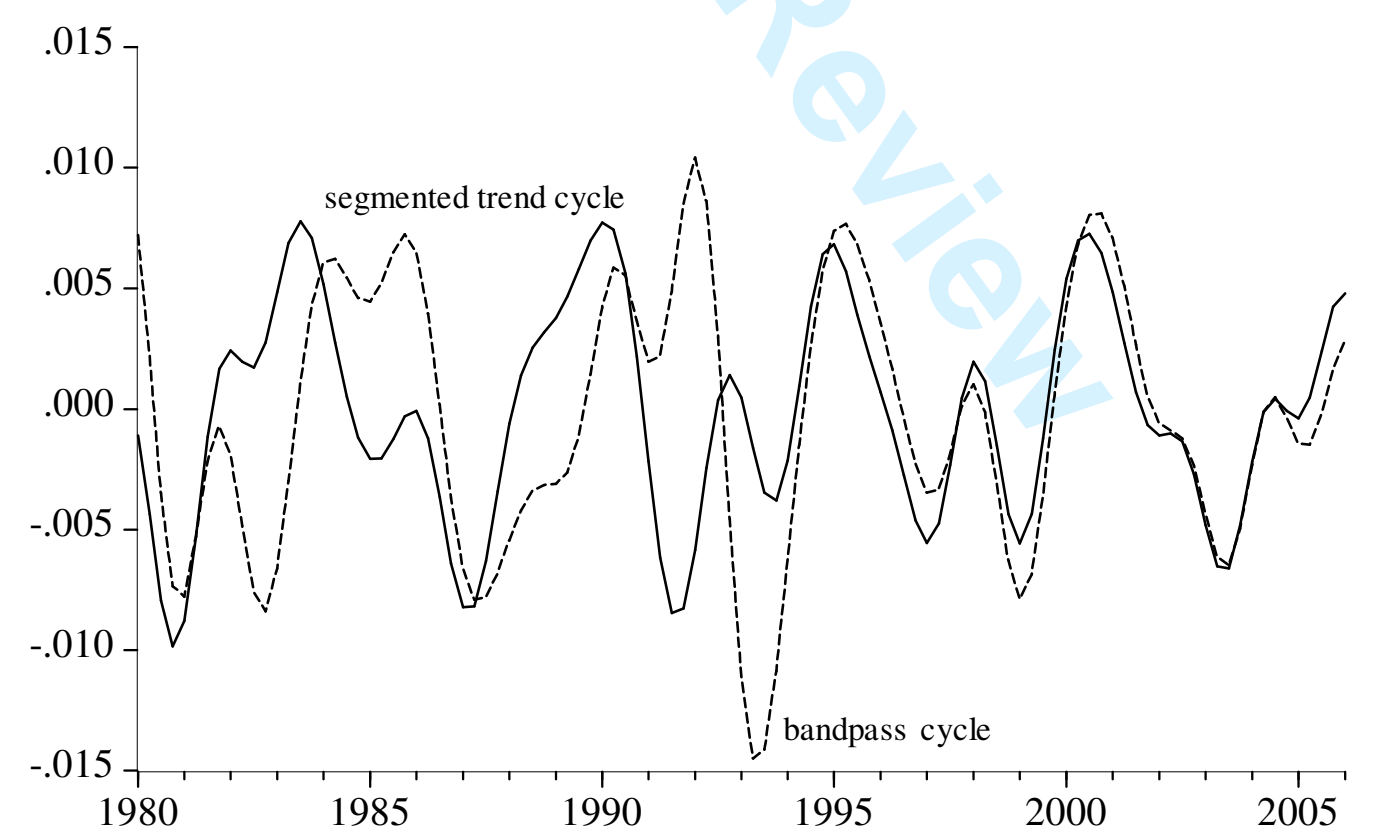

Figure 4 Cyclical components from the two models. 